\title{
Framing ethical isomorphs in educational leadership: A sociological approach
}

\section{Key words}

Democratic Republic of Congo; England; Ethical isomorphs; School leadership; Structuration theory; Ubuntu; Values.

This commentary is inspired by Begley's (2000) definition of (ethical) isomorphs as: 'Social conditions or value postures that appear to share the same shape or meaning in different countries but actually consist of quite different elements' (p. 23). I take this to mean that the value of 'rule of law', for example, may have the same meaning in different countries in terms of nation states organising themselves around certain laws. However, such laws are arrived at, understood, and applied differently. In reality, this means recognising common features of various values while accepting their different contextual nature. This is not only contested by the proponents of clear cut and incommensurable cultures, values and worldviews between groups of people (e.g. Dixon, 1977), it is also not straightforward an exercise to work out the common in contrasting value systems.

That said, Begley's (2000) primary concern in coming up with the concept of isomorphs is to ensure that school leaders are culturally attuned to local subtleties in the face of the tyranny of Western value considerations. However, given the realities of locally engineered tyrannies and the need to be inclusive in an increasingly globalised world, I suggest a sociologicallybased approach to the valuation of ethical isomorphs.

To illustrate my point, I use a 4-year study (Elonga Mboyo, 2017) that I undertook of four urban primary head teachers' experiences of school leadership in the Democratic Republic of Congo and England. Although cases are drawn mainly from England and the Democratic Republic of Congo, they could resonate in other contexts. I employed 'leadership conversations' as a research method. Its open, dialogical and co-constructional approach allowed multiple entry points and formats and was not only logistically practical but also proved critical in generating rich and valuable data. Its story telling, narrative nature was well received by two pairs of urban primary head teachers in two completely different settings: the Democratic Republic of Congo and England. As in other studies, including that of Campell 
et al. (2003), conversations proved to be an essential methodological tool when seeking to investigate roles and reflect on the values of school leaders.

The main study represents another entry in comparative educational leadership at the international level. The field faces a variety of challenges. Some of these challenges relate to the paucity of overall conceptual frameworks in international educational leadership (Dimmock \& Walker 2000) and the difficulty of articulating a coherent approach to common ethical values (Halstead 1996) in a world that is full of diverse and often competing (extreme) values.

My study proposed a conceptual framework that could serve as the basis for a comparative leadership theory and practice, grounding the work of comparatively skilled (school) leaders nationally and internationally. Here, however, I focus on a rather small but crucial aspect of that research: inclusivity identified among other core values of risk taking, integrity and success-mindedness, hereafter framed as a question. How could a head teacher in an increasingly globalised world, lead a culturally and ethically diverse school inclusively? How does he/she work out the common in contrasting value systems?

With this in mind, I provide a synopsis of the literature on the place of values in school leadership. Then, I discuss some ethical theories, including Begley's (2000) framing of ethical isomorphs. A critique of Begley's framework leads to the final part of this paper where I discuss the historical development and the essence of my Fear and Self-scrutiny model (Elonga Mboyo, 2016b) as a viable isomorphic ethical framework. I apply the framework to different cases to illustrate the changing nature of values that shape the work of school leaders operating in various ontological spaces. Such an exercise, I hope, will enable school leaders to engage in dialogues that have a clear idea about shared ontological spaces 'shared shape or meaning' to use Begley's terms - while accommodating contrasting elements.

\section{Values in school leadership}

First, I present a non-chronological discussion about shifts in the perception of values in educational leadership and some unresolved issues that require further reflection. Except when school leadership is viewed as managerialism (Bush \& Glover, 2014), where professional practice is seen as a value-free technicist praxis that objectifies a field, much of the head 
teachers' work is, in essence, based on choices and considerations of 'desirability of alternative courses of action on a daily basis' (Leithwood et al., 1994, p. 98) and is entangled in human emotions and conflicts based on values. Dobson (1952, p. 49) suggested that 'a large portion of conflict around education .... is related to the problem of values'. This means that the human experience of leading schools is built on the empirical display of value systems of some kind.

Despite the attempt to place the human experience of leadership values at the centre of school leadership, school leadership values are most often discussed at a non-empirical level. Ribbins and Gunter (2002) plot Hodgkinson's (1991) discussions on school leadership values at the conceptual level, arguably because they have been derived from non-empirical studies. Such an analysis creates a perception that school leadership values are drawn from a priori and abstract considerations detached from the real world, even though Hodgkinson himself advocated for praxis, where theory is linked to practice. Many studies, including that of Norberg and Johansson (2007, p. 291), attest to the reality that '[individual] values are important and that they probably steer actions taken and, in turn, have an impact on how the leadership profession is performed'. Warwas $(2015$, p. 326) concluded that 'professional values - i.e. conceptions of desirable modes, means and ends in coping with the demands of one's professional activity - modify contextual influences on leadership behaviour by informing the value holder about appropriate and expedient responses to contextual prerequisites'. These authors echo others regarding the importance of personal values and their influence on actions and perceptions (e.g. Day et al., 2001; Woods, 2000).

Values are, therefore, no longer seen as abstract. They gain their prominence from their relatedness to lived experiences. The diversity of values is a theoretically basic and legitimate assumption that parties with a stake in the running of schools hold to motivate their sustained (political, social, economic, religious, ideological and cultural) interests in those institutions (Halstead, 1996). From a practical point of view, the diversity of values also brings a certain degree of complexity. For example, the personal values of professionals are central to the resilience and resistance of such values in the face of the dominant market-based value narratives in education. As a part of this larger project, highlighting personal professional values allows professionals running schools the agency to take back control from especially hierarchically-situated stakeholders such as governments and those operating on their behalf 
(Hooge et al., 2012). Such centralised approach is (Bush, 2014) creating cultures of performativity (Ball, 2003).

The market-based value of short-term measurable outcomes has often been viewed as competing with other values prioritising the long-term social/human development of the child. Gillboran and Youndell (2000) have reported contradictory policies and practices, while Parsons' (1999) earlier study had documented a tension between (measurable) educational attainment and social inclusion in the overall perception of effective school leadership in successful schools. The fact that some school leaders manage to resolve such tensions (Campbell, 2002) suggests that there is another way of leading schools with diverse, contrasting, competing and perhaps extreme values. But this cannot be achieved by ignoring the pervasive influence of school ethos on the practices of the members of the school (Munn et al. 2001), particularly the inclusion of pupils in challenging circumstances (Hatton 2013). Campbell et al. (2003) noted that a school ethos geared towards school outcomes does not exclude a commitment to social inclusion. In reality, an official ethos only highlights many supporting, and perhaps competing, values that might be lurking in the background.

At the organisational level, those other values might be those of teachers, students or parents. For Norberg and Johansson $(2007$, p. 292), the perceived ethical dilemma of various actors - politicians, super intendants, principals, newly appointed head teachers and teachers - was a 'variation between the experienced dilemmas by the different groups of school agents'. Hence, different stakeholders within an organisation pursue different interests and encounter ethical dilemmas, which may or may not be seen as such by others within the group.

Values from wider contexts affect schools. For example, Catholic schools with individual values have to find ways of incorporating mercy or forgiveness, following Pope Francis' decree that 2016 be the year of mercy. Despite its acceptance by the global Catholic community, its implementation in schools causes some tension when a stakeholder, a parent in this case, objects to forgiveness on the ground of self-defence, as I will illustrate later.

The national talk in England, in the wake of high profile cases of radicalisation, is that of 'fundamental British values' in order to foster a climate of cohesiveness among communities, although this has been viewed by some as further invasion of professional and pedagogic 
spaces (Lander, 2016). In the Democratic Republic of Congo, the national drive requiring schools to unite around the national flag was instituted to instil the values of nationalism and self-determination. Though this is well received by the patriots, others fear it to be an illconceived ideological move by a government suspected of being unwilling to commit to a peaceful and democratic transfer of power. Mercy, forgiveness, patriotism, selfdetermination, democracy and so on are some of the values that school heads might want shared. However, since a school leader's shared values can easily be contested by others, this raises questions about our understanding of these values and how we arrive at them. Below, I introduce some frameworks as presented by Northhouse (2013) before discussing Begley's (2000) framework.

\section{An isomorphic ethical framework}

Pluralist societies create a degree of uncertainty in school leaders (Zembylas \& Lasonos, 2010). Such uncertainty prompted Halstead (1996) to advocate for shared values, in spite of the difficulty of articulating a framework that would account for the diversity of values, particularly in schools. Northouse (2013) outlined two main ethical leadership theories that looked exclusively at actions to determine their teleological (egotistic, utilitarian and altruistic consequences of such actions) or deontological benefits (the rightfulness or wrongfulness of the action in itself). Packaged in leadership seminars and practical guide publications, these frameworks form the basis for promoting certain valued practices such as democracy, the rule of the state, religious and/or cultural laws and so on head teachers, authors and rooted in their experience either teleo-logically or de-ontologically. Useful as they may be, there is a danger of falling into the trap of extreme relativism or universalisation of values, depending on how far and deep such socially constructed values can be manipulated, coerced and/or negotiated.

Begley (2000) underscored a salient point about the dangers of imposing values, such as democracy, when such a concept and others, though similar, are understood and interpreted in different ways in different contexts. To navigate through various ethical isomorphs, Begley advocated some sophistication in educational leadership, based on sensitive and reflective practice. He drew from the work of Hodgkinson (1991) in order to provide 'useful metaphors for supporting the analysis of social situations in schools' (Begley, p. 28). He used two onionlike figures (below) to represent the perspective of the one individual (without the social 
context), and the (social) context/arena within which the individual is positioned. Here, the individual is invited to reflect on the motives that bring him/her to embrace the values, which shape his/her attitudes manifested in action. Figure 2 shows all that is going on with the individual in the first figure within the social arenas of practice of a group (family, peers, friends), the organisation (school, hospital, company), and the community and wider culture/society.

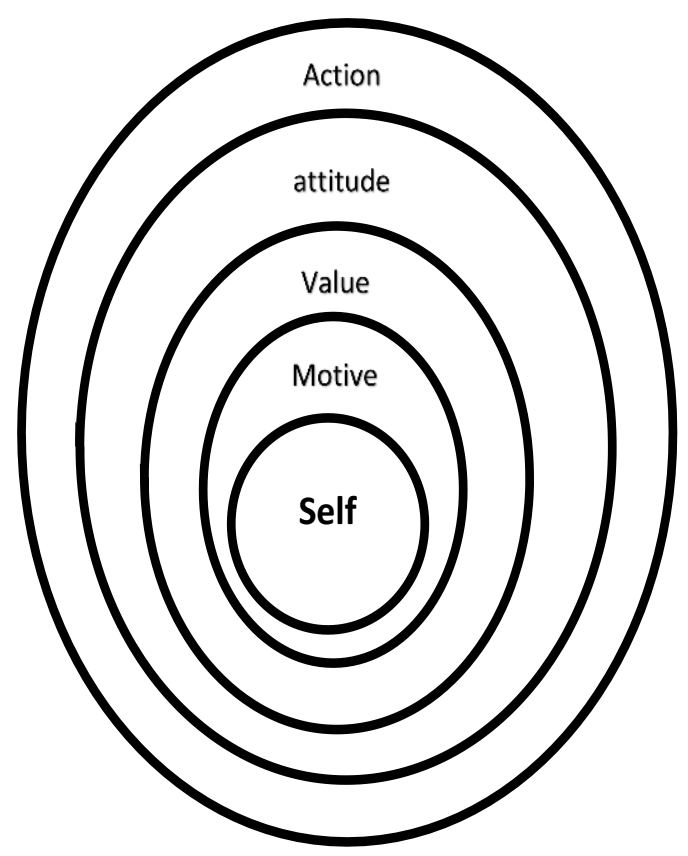

Figure 1: Schema of value terms (Begley, 2000, Figures 1 \& 2 used with permission)

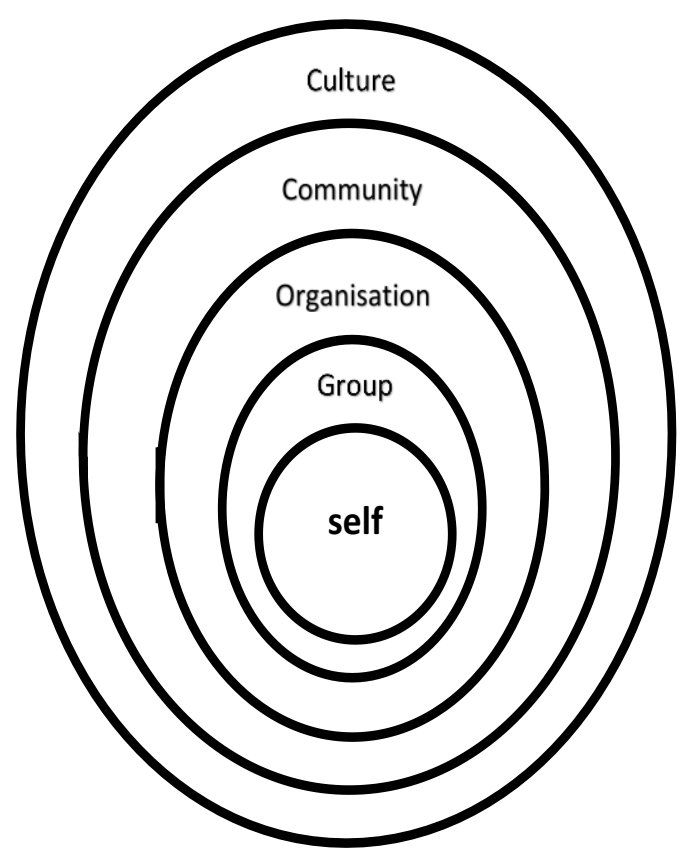

Figure 2: Arena of value actions

The model places the individual at the centre of the social architecture through his/her personal reflections on values. It represents a break from deterministic approaches to culture and recognises the role of school leaders in making moral decisions within the complex dimensions of culture (Collard, 2007). However, even Begley recognised some limitations of the model, particularly with regard to actions that have unobservable values and the variability and/or consistency of values and their universality. 
What is also important to note with Begley's (2000) approach is that ethical dilemmas are part of social situations and, as such, they ask us to ground the theorising and practice around leadership values on sociological concepts of what constitutes social reality. However, an analysis that subordinates the dynamics of the community (figure 2) to those of the individual (figure 1), as this framework seems to do, or vice versa, fails to capture the need for ontological inclusivity (subjectivism and communitarianism) in pluralist societies or schools. The model departs from attitudinal and motivational psychology-based stances/reflections and, in so doing, fails to articulate the sociological dimensions of, for example, community cultures that position the community as the starting point for the values and actions of individuals (Riessman, 2008). It is not so much a question of ontological complicity (Eacott \& Asunga, 2014), since Begley does not necessarily privilege subjectivism at the expense of communal worldviews. In his defence, he recommended "a proper appreciation of and sensitivity to the metavalues of organisations (communities and cultures)" (Begley, 2000, p. 30). The issue, in my view, lies with the apparent methodological silence of ontologies in both the Northern and Southern hemispheres.

Methodologically, then, it is unclear how head teachers are to go about constructing the metavalues in a way that adequately recognises the roles of individuals (agents) and communities (structures). An articulation of how one's worldview unfolds, then, plays an important role in framing ethical isomorphs that may be diverse in their configuration but similar in their fundamental nature. The question, therefore, is 'what do the chosen shared and all the other lurking values, presumably of the same shape but constructed of different elements, methodologically place school leaders and other stakeholders in defining the ontological social world that they want to help to create?' Here is where my Fear and Selfscrutiny model comes in.

The Fear and Self-scrutiny Model: towards a sociological isomorphic framework In The Constitution of Society, Giddens (1984) outlined his theory of structuration, which essentially states that social reality is derived from an interdependence of structure and agency, where agents shape and reshape the very structures of which they are part. That intersection of structure and agency is constraining and empowering at the same time. While Giddens' complex ontological characterisation of social reality has proven useful for research, some criticise him for failing to provide an equally robust methodological theory that would 
ground his rather abstract ontology. Stones' (2005) strong structuration theory, for example, is an attempt to move from ontology, in general, to ontology-in-situ. With that in mind, I want to discuss another subject of interest and link it with the above limitation of Giddens' theory. My interest in African studies, particularly in school and political leadership, has revealed that despite some ground-breaking attempts by Asante (1987), Dei (1994), Diop (1962), Mazama (2001), and Tempels (1959), for example, the field is still struggling to advance a coherent sociological worldview (Carroll, 2014). In response, I document various leadership examples in continental Africa, which, when analysed under the concept of Ubuntu, point to a methodology of Ubuntu (or structuration) (Elonga Mboyo, 2016b). It is worth noting that the scenario of a commensurate social theory of Ubuntu and structuration theory could be an unpalatable proposition for those who reject any rapprochement of inherent principles of social theory between the northern and southern hemispheres. I have rebutted such claims.

To briefly foreground the argument here, I reconsider the popularised African concept of Ubuntu with its related values of collectivism, humanism, interdependence etcetera (Littrell et al., 2013), which, in my view, are stacked together in a non-elaborative amalgamation with no clear demonstration of how they work together in daily life. I begin from the value of interdependence and work out how all the other Ubuntu-related values can be conceptualised. Using examples of leadership (words and actions) of Ubuntu prototypes, such as that of Nelson Mandela, I posit that the Ubuntu value of interdependence, not only between individuals but also between force-beings (structures and agents), was based on two key tenets: fear (for agents) and self-scrutiny (for structure, institutions or other individuals that represent it). Fear and self-scrutiny, as shown in the figure below, are both constraining and enabling/empowering. I argue that when Ubuntu or structuration theory are methodologically in operation, they engender four different forms of ontologically-configured interactions between agents and structures, and the only time both are enabling/empowering is at Quadrant 4, when agents are low in fear and structure/others is high in self-scrutiny. Whether one is using leadership examples, as I do (Elonga Mboyo, 2016b), or exclusively reflecting on modern social issues for global citizenship (that could be incorporated in school citizenship curricula), as I have done elsewhere (Elonga Mboyo, 2016a), one may use the Fear and Self-scrutiny model to explore other areas of life. The key tenets of the methodology of Ubuntu/structuration, as they appear on the figure below, 
remain the same. All of the quadrants produce their versions of ethical isomorphs, founded on starkly contrasting ontological relationships between structures and agents. I will elaborate on the nature of leadership values, based on interactions in all four scenarios (quadrants).

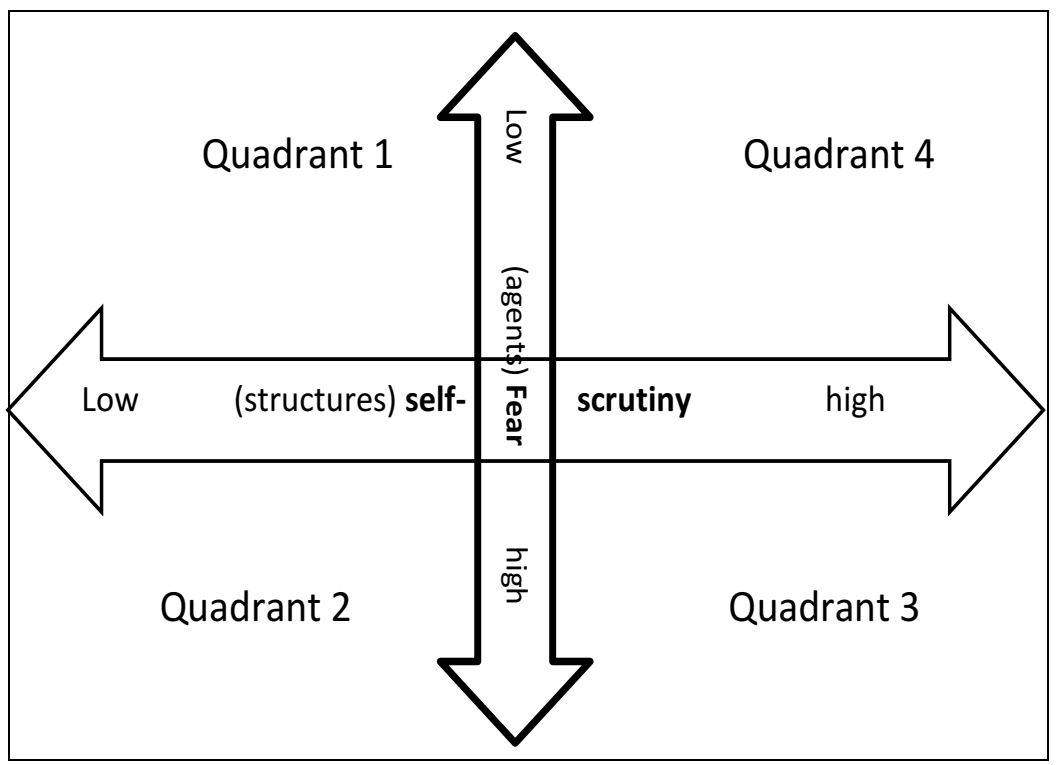

Figure 3: Fear and Self-scrutiny Methodology of Ubuntu/Structuration framework (Elonga Mboyo, 2016b)

I will now demonstrate using examples from my wider study (Elonga Mboyo, 2017), as well as some evidence as reported in The Guardian (2016) and The Times Educational Supplement (Milne, 2008), to reflect on the nature of ethical isomorphs that can emerge from these ontological spaces. It is possible to approach this by looking at how a single story (ethical decision/dilemma) can fit into all parts of the model. Alternatively, a value analyst (head teacher, leadership consultant, researcher, and so on) can use different examples to look back or look forward when thinking, agreeing on, explaining, and debating the value basis of planned or contingent social interactions in schools and in other fields. I make no explicit reference to DiMaggio and Powell's (1983, pp. 150-152 also cited in Puttick, 2017, pp. 66-72) three dimensions of institutional isomorphism: coercive isomorphism ('pressures felt as force, as persuasion, or as invitations to join in collusion'), memetic isomorphism (where 'uncertainty is a powerful force that encourages imitation...[w]hen organisational technologies are poorly understood...[or] when goals are ambiguous') and normative isomorphism (where closely guarded professionalization processes produce a pool of almost 
interchangeable individuals who occupy similar positions across a range of organisations and possess a [high level of] similarity of orientation and disposition') in the upcoming analysis. However, you are invited to bear those useful constructs in mind and integrate them accordingly.

Quadrant 1: As illustrated in figure 3, ethical isomorphs in this ontological space would be defined by a naïve sense of lack of fear for agents, while leaders operate with lack of selfscrutiny.

The case of recent instability in Burundi that resulted from whether the current Burundian president should be permitted to run for a second term or not is a fitting example for use when discussing values in Quadrant 1. Those in schools, undoubtedly, have to adjust to various national value narratives. It is within this atmosphere of tension and division that 17 school children were (recently) suspended, expelled or imprisoned for defacing a photograph of the president in their text books. The following extract encapsulates the general mood:

'After God came the king. Today we have no kings; it is the president who replaced them...' laments one Burundi resident (The Guardian, 2016)

Back in the era of kingships and divine rule, agents were likely not to lament but instead content with the rule of gods/kings, without necessarily having a clear idea of what they stood to benefit from such divine rule. If we substitute the gods and kings for leaders, then questioning the nature of interactions between agents and their leaders, who presumably derive their powers from gods, could be wrongly misinterpreted as an attack on the intrinsic nature of local cultures and religions. However, the point I want to underscore here is that the value of allegiance, respect and worship of god-like leaders can be framed as occurring amongst agents who are portrayed as being in low-fear state (See Quadrant 1) and 'happily' engaging with these values despite the lack of scrutiny from the other, whether an individual, president of a country, a school leader, or even a colonial master. On the subject of colonial education, Bafote in Elonga Mboyo (2017) talked about the education system in the time of the Belgian Congo in glowing terms as a system that privileged a sound moral attitude and saw it as being in direct contrast to the current Democratic Republic of the Congo's social fabric. This is despite colonial education system that sought to control a potentially subversive colony (Depaepe \& Hulstaert, 2015) 
Gunter and Thomson (2010) drew attention to vibrant historical debates around school leadership in the 1970s in England. The spirit and knowledge accumulated then, they suggested, are needed in the current environment, where headship is increasingly about leading national reforms at the local level. The historical analyses not only uncover felicitous practices; but also help to realise that some of the nostalgia associated with 1970s schooling is rooted in the unquestioning obedience and submission to school values, as promoted by head teachers. In my professional life as a teacher, I have heard teachers express nostalgia for those days when 'parents apologised for their child's poor behaviour and thanked you (the teacher) for punishing them'. Such nostalgia somehow betrays a deep yearning to socialise and even idolise certain unscrutinised (school leadership) values, whether of the past or still ongoing. Grace's (1995) description of the English educational environment points to possible low-fear and low-scrutiny educational values emerging from such an ontological space. For this author:

The cult of the public headmaster (or any policy, values or personality like the president of a country in various contexts) in England may have transformed over time as the class structure of which it was part has been transformed, but these phenomena, it can be claimed, are still potent features in the constitution of English society and schooling (p. 11). Emphasis added.

If we look at the general day-to-day life in a school today, we are likely to find examples of members of a school community who are religiously committed to the inflexibility/rigidity or laissez faire nature of various aspects of their schools. Children on the playground sometimes freely and happily socialise with a covertly uncaring bully, who sometimes directs offensive language at them that they have to take as humorous pleasantry. The nature of learning (as a process and outcome), produced by values caught up in this ontological space comes in the form of revealed commandments that a happily naïve agent absorbs without questioning.

Quadrant 2: Ethical isomorphs espoused by leaders motivated by this ontological space place agents in high fear, while the leaders remained in low scrutiny (See figure 3).

To illustrate this better, a second look at the extract from Quadrant 1 is required. Notice that the divine-like allegiance to the country's president by all, including pupils, is not a covert requirement but an open one, to which agents are no longer happily and unquestionably 
subscribing. The national value of respecting the head of state is openly imposed on pupils, who are arguably beginning to question the narrative. They are interrogating official values by defacing the image of the president in a text book. Attempts by agents to engage with the process used to promote such values are quickly suppressed by an openly oppressive other/institution, whose actions (the expulsion, exclusion and even imprisonment of such questioning agents) have the potential to move agents to high fear. School values here do not allow the space for people to engage in the process of the production of such values. Instead, learning has to be taken as an outcome, without questioning how such understanding was derived.

Reports from the English school environment present a narrative of various pressures that put a 'strain on [school] leaders with a job to do', who then turn to their teachers and support staff to perform. In some cases, as documented by Milne (2008), schools are 'run on fear' and support staff, who are 'intimidated by demonic headmasters', are 'scared to do anything because of repercussions'. The pursued value here, whatever it may be, is built around unquestioned or unscrutinised leadership demands on highly fearful agents - the staff and other agents.

Quadrant 3: Here, agents are still in high fear while leaders want to be perceived to have moved to a high scrutiny mode that, in reality, is self-serving (See figure 3).

The following extract from Bafote (Elonga Mboyo, 2017) is a good starting point for discussions about values developed within this quadrant. The Democratic Republic of Congo government recently issued a directive requiring schools to create pupils' parliament that would not only give pupils a voice but also instil a sense of identity around national heroes. Commenting on the swearing in ceremony of the new structures, Bafote stated that:

After we had all the elected members, we invited the parents to come in and witness the swearing in ceremony when we had to sing the national anthem. It was beautiful and the parents were proud to see their children embody the national patriotic values of our heroes such as Lumumba, Laurent Désiré Kabila.

Bafote spoke proudly of how well the students had internalised the government call to patriotism, by forming a school council with a president, members of parliament and so on. It has to be said that the national political ambiance in the Democratic Republic of Congo is unstable, fuelled by accusations that the incumbent head of state intends to stay in power, 
one way or another, beyond his second and final term, in contra to the country's constitution. The value of patriotism can then be seen as an attempt by politicians to implement such hidden agenda, or alternatively can be seen as being used by their opponents to level unsubstantiated accusations.

The social interactions generated by values of this ontological space seem to leave a perception among agents that the learning is about the process, whose outcome is determined by a seemingly scrutinising other/structure, but only in so far as that scrutiny achieves their own agenda. The singing of the national anthem around the country's flag in Baf (one of the researched Democratic Republic of Congo schools), then, according to a section of the population, seems to be a process designed for a premeditated outcome only known to those behind the structure (i.e., allegedly holding onto power). Despite an apparent structural scrutiny, agents are now worried and fearful of the ulterior motives behind such values. It might be helpful to think of the interminable testing, performance management and inspection regimes in the English educational environment, for example, or other similar contexts that leave agents in high fear, while a structure (whatever body it may be) gives what might be deemed as 'biased' justification of quality assurance and so on.

At this stage some school agents whether staff or pupils, dare to question and challenge the values that have contributed to their high fear, as in Milne's (2008) article, where support staff reportedly challenged the bullying regimes in their schools, earning them this response from the head teacher's union: '...the support staff...are being oversensitive'

This response is a justification many would describe as self-serving scrutiny that goes as far as discrediting the agents in question, instead of genuinely engaging them in a fearless and self-scrutinising process of shaping and reshaping of their schools' (meta) values.

Quadrant 4: This is the quadrant where genuine dialogue begins when agents in low fear seek clarity and engagement in educational public institutions and leaders respond with genuine and collaborative high scrutiny (See figure 3).

The values talked about by the English research participants (Fiona and Donald in Elonga Mboyo, 2017) were partly centred on the British values of democracy, rule of law, individual liberties, mutual respect and tolerance of those with different faiths and beliefs. Donald said that: 
British values' is something that the government is concentrating on. They don't differ from the values we've had all the time, you have to say them in a different way... Yes we could say that our British values are core whether we are British or not, we are buying into the values that we might all have. (Donald)

Despite Donald's claim of the universal nature of 'British values', the basis upon which such a claim stands and can be operationalised in schools was not clearly articulated. It is now widely accepted that different people give different meanings to values such as democracy. It would, therefore, become a counterproductive assimilationist approach (Goddard \& Hart, 2007) for school leaders to engage in a process that seeks to erase inherent differences without engaging with such values in order to establish their ontological underpinnings and work out whether one needs an ontological shift or simply to accommodate and celebrate a different meaning of the same concept. Hence, the 'British values' as ethical isomorphs in schools can be viewed as contextually different in meaning, but ontologically structured in the same way as those democracies in other societies that aspire to (or are built on) Quadrant 4 of the Fear and Self-scrutiny model. Here, values of academic excellence, human development, forgiveness, self-defence and others that are enshrined in a school ethos, religious text and so on are included in a joint ongoing deliberation between agents and structures concerned with an atmosphere of low fear and high self-scrutiny.

Both the Democratic Republic of Congo and English heads in my study displayed openly articulated values with Quadrant 4 features. However, this analysis clarifies the head's responsibility in addressing ethical dilemmas by turning potential Quadrant 1, 2 and 3 isomorphs into Quadrant 4 ones. The suggestion of high scrutiny may be misinterpreted by some as further erosion of autonomy which, in reality, cannot be gained in absolute terms (Simkins, 2003) and may place the school head in conflict with stakeholders who are operating from a different ontological space, one which requires the skill, determination, sensitivity and risk-taking as well as the education/induction of all stakeholders into Quadrant 4 of the methodology of Ubuntu as I have attempted to show (Elonga Mboyo, 2016a).

The same principles apply when talking to head teachers, teachers, students and parents about various responses to situations. I invite you to work out a way of initiating a dialogue aimed at bringing others (parents or students) to embrace Quadrant 4 key tenets (low fear and high scrutiny) in the face of the following ethical dilemma: 
A fight was reported to have happened between two children. Standard practice after stopping the fight is to establish what led to it and who was responsible. At this stage, cracks began to appear in the way that parents perceived the way I was going about it. Forgiveness is what we are about. I was happy to have brought the warring children to say sorry to each other. Some parents, however, deemed it inappropriate that their child was being asked to apologise when, according to them, the child was only defending him(her) self. (Donald)

In considering this case, practitioners will undoubtedly consider the nature of the discussions; the (tone of) the language used; the resources made available, the information provided in terms of policy, what the law says on certain issues; the questions asked, the answers given; the understanding/knowledge gained; actions taken and so on. It may be impossible for well-intentioned structures to gauge just how fearless agents are to hold structures into account. In the same vein, agents may not gain an accurate measure of structures' intention to be genuinely self-scrutinising. The fear and self-scrutiny model, therefore, is the measure that both parties can use to resolve the above and similar dilemmas while ensuring that co-constructed values are configured at quadrant 4.

You also may wish to reconsider the widely talked about value of distributed leadership, for example, that has worked in some cases (Bush \& Glover, 2012; Harris, 2008; 2010), and prove ineffective in others (Phillips, 2001). Lumby suggested that 'distributed leadership theory renders discrimination practice invisible' $(2013$, p. 590$)$. The challenge for us is to assess how such a potential isomorph can be uniquely applied in different contexts within the same ontological structure of Quadrant 4, as well as how it could produce different results if enacted within Quadrants 1, 2 and 3. Considering Begley's (2000) earlier discussion, I would contend that his rather psychological framework, based around individuals' motives, can be integrated here as a useful exercise undertaken at quadrant 4 to ensure that the value (motives, attitude and action) under deliberation happens within the ontological space to which a society aspires.

\section{Conclusion}

I have argued here for an approach to school leadership that departs from acknowledging the multiplicity of values of diverse stakeholders. Despite the expressed desire for more autonomy in schools, scholarly work still reports increased central government control on schools in England (Gunter, 2011; Hammersley, 2015), which makes it comparable to most African countries with centralised education systems (Bush \& Glover, 2014; Bush \& Glover, 2016; Kambanda, 2013). Since complete autonomy cannot be achieved (Simkins, 2003) - and 
the same could be said of complete control - choosing appropriate values for any given time and space is a democratic process that follows certain key social tenets of fear (for agents) and self-scrutiny (for structures), owing to the commensurate worldview of structuration theory and Ubuntu.

In light of the methodology of Ubuntu/structuration as expressed in the Fear and Self-scrutiny model, not all cultural values are ontologically structured in the same way. It could help, therefore, to conceptualise ethical isomorphs as values that may carry the same or different meanings but that are ontologically structured in the same way. Let us assume that most, if not all, societies founded on the ontology of Ubuntu and/or structuration theory aspire to operationalise that collaborative vision within Quadrant 4 of the Fear and Self-scrutiny model. The challenge for school leaders would be, therefore, to align their chosen values to that particular ontological space, while ensuring that sensitivity to theirs and other's (meta) values does not equate to leaving structures and agents to operate within the non-emancipatory and dehumanising ontological spaces of Quadrants 1, 2, and 3.

Decisions will have to be made as to which Quadrant-4-based values can be pursued in organisations such as schools with hundreds of members, each possibly demanding that their Quadrant 4 values be promoted. Beyond that, the process of inducting others into Quadrant 4-based ethical isomorphs can be long and fraught with conflict, especially if one finds him/herself in a national and/or international political or religious context that seeks to steer the masses to Quadrants 1, 2, 3 value-based ideologies. Despite using examples from educational leadership, the case made for ethical isomorphs here may prove useful to professionals in other fields as well. It is also my conviction that methodological and ontological discussions of any study should not only end at the research design stage. Researchers using this or any other framework as an investigative tool should also make an analytical judgement about which of the methodology of Ubuntu inspired ontological spaces would have structured the interactions that would have led to any given research findings. That way, the value of research findings will not only be stated, but also allow the audience to engage with the ontological configuration of various claims.

\section{References}

Asante, M. (1987) The Afrocentric Idea. Philadelphia, PA: Temple University Press. 
Begley, P. (2000) Cultural isomorphs of educational administration: reflections on Westerncentric approaches to values and leadership. Asia Pacific Journal of Education, 20 (2), 23-33.

Bush, T. and Glover, D. (2012) Leading high performing leadership teams in English schools. School leadership \& Management, 32 (1), 21-36.

Bush, T. and Glover, D. (2014) School leadership models: what do we know? School leadership \& Management, 34 (5), 553-557.

Bush, T., \& Glover, D. (2016). School leadership in West Africa: Findings from a systematic literature review. Africa Education Review, 13 (3-4), 80-102.

Campbell, C. (ed.) (2002) Developing Inclusive Schooling: Perspectives, Policies and Practices. London: University of London, Institute of Education.

Campbell, C., Gold, A. and Lunt, I. (2003) Articulating leadership values in action: conversations with school leaders. International Journal of Leadership in Education, 6 (3), 203221.

Carroll, K. K. (2014) An introduction to African-Centered sociology: worldview, epistemology, and social theory. Critical Sociology, 40 (2), 257-270.

Cowling, V., Costin, J., Davidson-Tuck, R., Esler, J., Chapman, A. and Niessen, J. (2005) Responding to disruptive behaviour in schools: collaboration and capacity building for early intervention. Australian E-Journal for the Advancement of Mental Health, 4 (3), 183-190.

Day C, Harris, A. and Hadfield, M (2001) Challenging the orthodoxy of effective school leadership. International Journal of Leadership in Education, 4 (1), 39-56.

Dei, J.G. (1994). Afrocentricity: A cornerstone of pedagogy. Anthropology and Education Quarterly, 25 (1), 3-28.

Depaepe, M. and Hulstaerk, K. (2015) Demythologising the educational past: an attempt to assess the 'power of education' in the Congo (DRC) with a nod to the history of interwar pedagogy in Catholic Flanders. Paedagogica Historica, 51 (1-2), 11-29.

DiMaggio, P. J., and Powell, W. W. (1983) The iron cage revisited: institutional isomorphism and collective rationality in organisational fields. American Sociological Review 48 (2), 147-160.

Dimmock, C. and Walker, A. (2000) Developing comparative and international educational leadership and management: A cross-cultural model. School Leadership and Management, 20 (2), 143-160.

Diop, A. C. (1962) The Cultural Unity of Negro Africa. Paris: Presence Africaine.

Dixon V J (1977) African-oriented and Euro-American-oriented worldviews: research methodologies and economics. The Review of Black Political Economy, 7 (2), 119-156.

Dobson, W. D. (1952) Values in education. The Journal of Educational Sociology, 2 (2), 49-50, 96. 
Eacott, S. and Asunga, G. N. (2014) School leadership preparation and development in Africa: a critical insight. Educational Management, Administration \& Leadership, 42 (6), 919-934.

Elonga Mboyo, J. P. (2016a) Trapped? Empowering Communities to Face Modern Day Vulnerabilities of Exclusion, Extremism, Radicalisation, Terrorism, Grooming, Addiction and Bullying. United Kingdom: Vetmaf.

Elonga Mboyo, J. P. (2016b) Africa through Structuration Theory: Outline of the FS (Fear and Self-scrutiny) Methodology of Ubuntu. $2^{\text {nd }}$ ed. Cameroon: Langaa RPCIG.

Elonga Mboyo, J. P. (2017) Comparative Leadership: Pathways, Scope and Values in DRCEnglish 'Urban' Schools. Sheffield Hallam University, UK: Unpublished Doctoral Thesis.

Giddens, A. (1984) The Constitution of Society. Cambridge: Polity.

Gillborn, D. and Youndell, D. (2000) Rationing Education: Policy, Practice, Reform and Equity. Buckingham: Open University Press.

Goddard, T. J. and Hart, A. C. (2007) School leadership and equity: Canadian elements. Educational Leadership \& Management, 27 (1), 7-20.

Grace, G. (1995) School Leadership - Beyond Education Management. London: Falmer.

Guardian (The) (2016) School pupils arrested in Burundi for defacing photos of president. https://www.theguardian.com/world/2016/jun/07/school-pupils-arrested-burundi defacing-photos-president-pierre-nkurunziza?CMP=share btn $\mathrm{fb}$

Gunter, H. M. (2011) Leadership and the Reform of Education. Bristol: Policy Press.

Gunter, H. M. and Thomson, P. (2010) Life on Mars: headteachers before the national college. Journal of Educational Administration and History, 42 (3), 203-222.

Halstead, M. J. (1996) Values and values education In M. J. Halstead and J. M. Taylor, (eds) Values in Education and Education in Values. London: The Falmer Press.

Hammersley F. L. (2015) Value(s)-driven decisionmaking: The ethics work of English headteachers within discourses of constraint. Educational Management, Administration \& Leadership, 43 (2), 198-213.

Harris, A. (2008) Distributed leadership: according to evidence. Journal of Educational Administration, 46 (2), 172-178.

Harris, A. (2010) Distributed leadership, In T. Bush, L. Bell and D. Middlewood, (eds.) Principles of Educational Leadership and Management. London: Sage. 55-69.

Hatton, A. L. (2013) Disciplinary exclusion: the influence of school ethos. Emotional and Behavioural Difficulties, 18 (2), 155-178.

Hodgkinson, C. (1991) Educational Leadership: The Moral Art. Albany: State University of New York Press.

Hooge, E., Burns T. and Wilkoszewski, H. (2012) Looking beyond the numbers: Stakeholders and multiple school accountability, OECD Education Working Papers, No 85, OECD Publishing. 
Kambanda, S. (2013) The role of high school principals in leading and managing school cultures: A case study of Huye district in Rwanda. Unpublished PhD thesis, Johannesburg, University of the Witwatersrand.

Lander, V. (2016) Introduction to fundamental British values. Journal of Education for Teaching, 42, 3, 274-279.

Leithwood, K., Begley, P. and Cousins, J. B. (1994) Developing expert leadership for future schools. London: the Falmer Press.

Littrell, F. R., Wu, H. N., Nkomo, S., Wanasika, I., Howel, J. and Dorfman, P. (2013) Pan-SubSaharan African management leadership and the values of Ubuntu. In Lituchy, R. T. et al. Management in Africa, Macro and Micro Perspectives. London: Routledge. 232-248.

Lumby, J. (2013) Distributed leadership: the uses and abuses of power. Educational Management, Administration and Leadership, 41, 5, 581-597.

Mazama, A. (2001) The Afrocentric paradigm: contours and definitions. Journal of Black Studies, 31, 387-405.

Milne, J. (June $20^{\text {th }} 2008$ ) Support staff 'bullied by demon heads'. The Times Educational Supplement, 4793.

Munn, P., Cullen, M. A., Johnstone, M. and Lloyd, G. (2001) Exclusion from school: a view from Scotland of policy and practice. Research Papers in Education, 16 (1), 23-42.

Norberg, K. and Johansson, O. (2007) Ethical dilemmas of Swedish school leaders. Educational management Administration \& Leadership, 35 (2), 277-294.

Northouse, G. P. (2013) Leadership: Theory and Practice. $6^{\text {th }}$ ed. London: Sage.

Parsons, C. (1999) Education, Exclusion and Citizenship. London: Routledge.

Phillips, V. (2001) Leading in education - flavour of the month or serious business? Nottingham: National College for School Leadership. http//www.scsl.org.uk

Puttrick, S. (2017) 'You'll see that everywhere': institutional isomorphism in secondary school subject departments. School Leadership and Management, 37:1-2, 61-79.

Ribbins P. and Gunter, H. (2002) Mapping leadership studies in education: towards a typology of knowledge domains. Education Management \& Administration, 30 (4), 359-385.

Riessman, K. C. (2008) Narrative Methods for the Human Sciences. London: Sage.

Simkins, T. (2003) Reform, accountability and strategic choice in education. In Preedy et al. (eds). Strategic Leadership and Educational Improvement. London: Paul Chapman Publishing.

Stones, R. (2005). Structuration Theory. Basingstoke: Palgrave Macmillan Routledge.

Tempels, P. (1959) Bantu: Philosophy. Paris: Presence Africaine. 
Warwas, J. (2015) Principals' leadership behaviour: values-based, contingent or both? Journal of Educational Administration, 53 (3), 310-334.

Woods, P. (2000) Varieties and themes in producer engagement: structure and agency in the schools of public-market. British Journal of Sociology of Education, 21 (2), 219-242.

Zembylas, M. and Lasonos, S. (2010) Leadership styles and multicultural education approaches: an exploration of their relationship. International Journal of Leadership in Education, 13 (2), 163-183. 